\title{
KONDISI TEGAKAN MERANTI MERAH (Shorea parvifolia DYER ) UMUR 13 TAHUN PADA HUTAN BEKAS TERBAKAR DI SAMBOJA, KABUPATEN KUTAI KARTANEGARA, KALIMANTAN TIMUR
}

(Stand Condition of Meranti Merah (Shorea parvifolia Dyer) 13 Years Old at the Burn-forest Area in Samboja, District of Kutai Kartanegara, East Kalimantan)

\author{
Oleh/By: \\ Ayi Suyana dan Abdurachman \\ Balai Besar Penelitian Dipterokarpa
}

\begin{abstract}
Activity rehabilitates ex forest be a-fire good demulcent, be and also heavy at one particular place need by undertaking been done instilling effort with various plant genus especially local original type needs to be done. This research is executed on ex forest acreage burnt by weight. The purpose of this research was to know condition stand of meranti merah (Shorea parvifolia Dyer) on ex acreage to be burnt weight at the age 13 years. The result that Stand was Bells or normal curve. Increment of diameter rate was $1.22 \mathrm{~cm}$ per year and $1.24 \mathrm{~m}$ per year to high. Tree can be said slim enough with comparation rate height and diameter was 107.96.
\end{abstract}

Key Words : Structure, stand, meranti merah (Shorea parvifolia Dyer), increment.

\begin{abstract}
ABSTRAK
Kegiatan merehabilitasi hutan bekas terbakar baik ringan, sedang maupun berat pada suatu tempat perlu dilakukan dengan melakukan usaha penanaman dengan berbagai jenis tanaman terutama jenis asli setempat. Penelitian ini dilaksanakan pada areal hutan bekas terbakar berat. Tujuan dari penelitian ini adalah untuk mengetahui kondisi tegakan meranti merah (Shorea parvifolia Dyer) yang ditanam pada areal bekas terbakar berat pada umur 13 tahun. Hasil pengamatan menunjukkan bahwa struktur tegakan memiliki bentuk genta atau kurva normal. Nilai rataan riap pertahun sebesar $1,22 \mathrm{~cm}$ untuk diameter dan 1,24 $\mathrm{m}$ untuk tinggi. Pohon dapat dikatakan cukup ramping dengan rataan nisbah tinggi dengan diameter sebesar 107,96.
\end{abstract}

Kata Kunci : Struktur, tegakan, meranti merah (Shorea parvifolia Dyer), riap. 


\section{PENDAHULUAN}

Shorea parvifolia Dyer atau di dunia perdagangan kayu dikenal dengan meranti merah, termasuk salah satu jenis bahan baku industri perkayuan baik di dalam maupun di luar negri. Jenis ini termasuk keluarga Dipterocarpaceae yang secara alami mempunyai penyebaran yang luas di hutan-hutan tropis dataran rendah dari ketinggian $400 \mathrm{~m}$ di atas permukaan laut. Di Indonesia banyak dijumpai terutama di Pulau Sumatera dan Kalimantan. Pohon ini memiliki ukuran yang sangat besar, tingginya dapat mencapai $65 \mathrm{~m}$ sedangkan diameternya $190 \mathrm{~cm}$. Dengan ukuran yang besar ini maka kayu ini sangat baik untuk bahan pertukangan. Biasanya digunakan untuk bangunan, kayu lapis, mebel, lantai, papan dinding dll. Berat jenis dari kayu ini adalah 0,45 (kisaran antara 0,29 - 0,83), dengan kelas keawetan III-V dan kelas kekuatan III-IV (Heyne, 1987; Anonim, 1994 dan Martawijaya et al., 2005).

Kebakaran areal atau hutan dapat terjadi kapan saja dan dimana saja, baik yang disebabkan oleh faktor kesengajaan maupun tidak dan juga bisa disebabkan oleh manusia maupun oleh alam karena disambar petir atau kemarau yang berkepanjangan yang dapat menimbulkan api akibat gesekan bahan kering yang ada di dalam hutan. Kebakaran hutan di Kaltim yang terjadi tahun 1982/1983 dan 1997/1998 membawa dampak bagi kerusakan areal, demikian hal ini terjadi pada areal demplot penelitian Samboja. Akibat dari kebakaran tersebut telah menyebabkan banyak hutan yang telah ditanam, bekas tebangan dan ladang yang rusak termasuk areal demplot penelitian Samboja.

Kegiatan merehabilitasi hutan bekas terbakar baik ringan, sedang maupun berat pada suatu tempat perlu dilakukan dengan usaha penanaman dengan berbagai jenis tanaman terutama jenis asli setempat. Usaha-usaha penanaman baik pada hutan alam dalam bentuk pengayaan dan rehabilitasi maupun membangun hutan tanaman membutuhkan berbagai informasi dari berbagai jenis tumbuhan.

Project ITTO PD 84/90 (F) phase 2 mencoba melaksanakan kegiatan rehabilitasi pada areal yang terbakar berat dengan menanam tanaman dari jenis meranti merah (Shorea parvifolia Dyer) dengan jarak tanam $6 \times 4 \mathrm{~m}$ sistem pemeliharaan yang dilakukan adalah dengan sistem jalur. Sehubungan dengan hal tersebut maka tulisan ini akan memberikan informasi tegakan tanaman dari jenis meranti merah (Shorea parvifolia Dyer) setelah penanaman pada umur 13 tahun.

\section{BAHAN DAN METODE PENELITIAN}

\section{A. Lokasi}

Secara geografis daerah penelitian ini berada sekitar $00^{\circ} 56^{\prime} 47.6^{\prime \prime}$ Lintang Selatan (LS) dan $116^{\circ}$ 59' 32.3" Bujur Timur (BT) dengan ketinggian antara 50 - 90 meter dpl. Kawasan hutan Bukit Soeharto memiliki jenis tanah podsolik merah kuning dan terletak di daerah lipatan dengan bentuk wilayah bergelombang sampai berbukit. 
Perkembangan profil tanah dari batuan liat dan batu pasir. Fraksi pasir terdiri dari kwarsa keruh dengan fragmen batuan kwarsit, konkresi besi dan mineral lapuk dengan kandungan mineral sangat rendah.

Tanah bagian atas mempunyai struktur rendah dengan konsistensi gembur sedangkan bagian bawah mempunyai struktur rendah sampai gempal dengan konsistensi gembur sampai teguh. Tekstur tanah lempung berdebu dengan laju perlokasi agak lambat.

Curah hujan rata-rata tahunan yang diambil dari stasiun klimatologi yang ada pada daerah ini adalah $2355,58 \mathrm{~mm} /$ tahun. Temperatur udara maksimum pada siang hari mencapai $32,77^{\circ} \mathrm{C}$ dan minimum $29,10^{\circ} \mathrm{C}$. Suhu udara maksimum pada malam hari adalah $24,26^{\circ} \mathrm{C}$ dan minimum $23,26^{\circ} \mathrm{C}$.

Kondisi awal dari lokasi ini adalah telah mengalami kebakaran yang berulang-ulang sehingga keadaannya dapat dikatakan seragam. Daerah ini sedikit lebih aman dalam arti telah mengalami suksesi yaitu suatu penggantian komunitas tumbuh-tumbuhan asli oleh yang lain. Hal ini dapat terjadi pada tahap integrasi lambat ketika tempat tumbuh mula-mula sangat keras sehingga sedikit tumbuhan yang dapat hidup di atasnya atau suksesi tersebut dapat terjadi dengan sangat cepat ketika suatu komunitas dirusak oleh suatu faktor seperti api, banjir atau epidemi serangga dan diganti oleh yang lain (Daniel T.W et al., 1987).

Lebih jauh lagi dijelaskan bahwa suksesi yang terjadi adalah suksesi sekunder yaitu terjadi karena adanya suatu gangguan, walaupun demikian jika kita lihat secara keseluruhan bagaimana daerah ini mengalami kebakaran yang berulang kali sehingga daerah ini mengalami kehilangan semua vegetasi, hal ini mendekati pada suksesi primer. Suksesi primer adalah suksesi yang dimulai dari suatu permukaan yang tidak bervegetasi seperti bukit pasir pantai, tanah longsor, aliran larva, permukaan batu atau bahkan kolam steril yang terbentuk karena gerakan gletser.

\section{B. Pengumpulan Data}

Data yang diambil dari penelitian ini adalah tanaman yang telah ditanam pada tahun 1994 dengan jarak tanam 4 × $6 \mathrm{~m}$, dari tanaman yang ada tersebut dilakukan pengukuran diameter dan tingginya secara sensus.

\section{Cara Pengukuran}

Pengukuran tinggi total pada semua pohon yang masuk dengan menggunakan clinometer. Nilai tinggi diperoleh dengan rumus :

$$
H=\frac{H_{t o p}-H_{b}}{H_{p}-H_{b}} \times \text { tinggi galah }
$$

$\mathrm{H}_{\text {top }}=$ Skala persen puncak pohon

$\mathrm{H}_{\mathrm{p}} \quad$ = Skala persen ujung galah 
$\mathrm{H}_{\mathrm{b}} \quad=$ Skala persen dasar pohon

Pengukuran diameter setinggi dada dilakukan dengan menggunakan alat ukur keliling, kemudian dikonversi menjadi diameter dengan cara membaginya dengan "phi” $(\pi)$ yaitu $3,14(\mathrm{dbh}=\mathrm{k} / \pi)$.

\section{HASIL DAN PEMBAHASAN}

\section{A. Sebaran Diameter}

Data hasil pengukuran di lapangan yang ditunjukkan pada Tabel 1 memperlihatkan data sebaran diameter yang dikelompokkan dalam kelas-kelas diameter dengan interval $5 \mathrm{~cm}$. Dalam kondisi yang lebih besar, sebaran diameter ini akan membentuk struktur tergakan seperti yang disampaikan Loetsch et al. (1973), yang menyatakan bahwa struktur tegakan atau hutan menunjukkan sebaran umur dan/ atau kelas diameter dan kelas tajuk. Lebih jauh dikatakan juga bahwa pembuatan distribusi diameter batang dilakukan dengan cara mengelompokkan data hasil pengamatan diameter di lapangan kedalam kelas-kelas tertentu. Selanjutnya disebutkannya jika pohon-pohon dari suatu tegakan dikelompokkan dalam suatu kelas interval diameter maka didapatkan distribusi diameter yang merupakan gambaran tentang struktur tegakan.

Tabel (Table) 1. Sebaran diameter tanaman meranti merah (Shorea parvifolia Dyer) di lokasi penelitian (Distribution of diameter of meranti merah (Shorea parvifolia Dyer) plantation in research field)

\begin{tabular}{|c|c|c|}
\hline $\begin{array}{c}\text { Kelas diameter } \\
\text { Diameter class }(\mathrm{cm})\end{array}$ & $\begin{array}{c}\text { Nilai tengah } \\
\text { (median) }\end{array}$ & $\begin{array}{c}\text { Jumlah pohon } \\
\text { (Number of trees) }\end{array}$ \\
\hline $0,00-4.99$ & 2.50 & 1 \\
\hline $5,00-9.99$ & 7.50 & 29 \\
\hline $10,00-14.99$ & 12.50 & 55 \\
\hline $15.00-19.99$ & 17.50 & 42 \\
\hline $20,00-24.99$ & 22.50 & 8 \\
\hline $25,00-29.99$ & 27.50 & 2 \\
\hline $30,00-34.99$ & 32.50 & 76 \\
\hline
\end{tabular}

Dari Tabel 1 tersebut terlihat bahwa jumlah pohon terbanyak berada pada kelas diameter pertengahan atau di antara diameter yang terbesar dan terkecil. Sedikit sekali pohon yang telah mencapai diameter diatas $20 \mathrm{~cm}$ walaupun umurnya telah mencapai 13 tahun. Pohon-pohon terbanyak pada kelas diameter $5-15 \mathrm{~cm}$. Dengan demikian sampai pada umur tersebut tegakan pada plot pengamatan ini tidak produktif untuk menghasilkan kayu.

Bentuk sebaran dari tanaman tersebut dapat dilihat pada Gambar 1 berikut ini. 


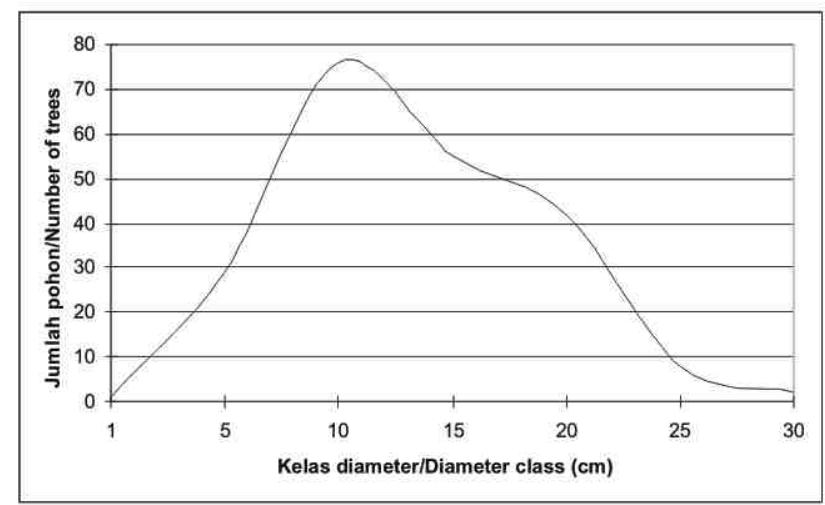

Gambar (Figure) 1. Kurva sebaran diameter tanaman Meranti merah (Shorea parvifolia Dyer) di lokasi penelitian. (Curve of diameter distribution of meranti merah (Shorea parvifolia Dyer) plantation in research field)

Pada gambar 1 tersebut terlihat bahwa kurva sebaran diameter hampir menyerupai bentuk lonceng/genta yang menyerupai sebaran normal. Kondisi kurva yang menyerupai lonceng/genta ini merupakan ciri dari hutan tanaman, seperti yang terlihat pada penelitian di hutan tanaman meranti di KHDTK Sebulu (Suyana dan Abdurachman, 2006), tanaman Acacia mangium di PT ITCI Kenangan (Rizal, 1987). Perlakuan di hutan tanaman adalah suatu usaha dalam rangka memperoleh hasil atau volume yang besar sehingga dalam proses yang lebih jauh pada hutan tanaman diperlukan suatu upaya untuk menggeser bentuk kurva ini pada area disekitar titik puncak kearah sebelah kanan pada sumbu X sehingga hasil produksi yang diperoleh menjadi besar. Demikian pula jika tanaman ini akan ditujukan untuk maksud tersebut maka pada tahap selanjutnya diperlukan perlakuan-perlakuan dalam usaha tersebut. Secara teoritis, teknik silvikultur diperlukan untuk menggeser kurva tersebut ke arah kanan.

\section{B. Statistik Tanaman}

Statistik diameter dan tinggi tanaman meranti merah (Shorea parvifolia Dyer) yang diukur pada umur 13 tahun disajikan pada Tabel 2.

Tabel (Table) 2. Statistik diameter dan tinggi tanaman meranti merah (Shorea parvifolia Dyer) di lokasi penelitian. (Statistics of diameter and height of meranti merah (Shorea parvifolia Dyer) plantation in research field)

\begin{tabular}{|l|r|r|r|r|}
\hline Peubah (variable) & $\begin{array}{l}\text { Rataan } \\
\text { (Mean) }\end{array}$ & $\begin{array}{l}\text { Maksimum } \\
\text { (Maximum) }\end{array}$ & $\begin{array}{l}\text { Minimum } \\
\text { (Minimum) }\end{array}$ & $\begin{array}{l}\text { Variasi } \\
\text { (variance) }\end{array}$ \\
\hline Diameter/dimater (cm) & 15.8 & 31.8 & 4.8 & 31.2890 \\
\hline Tinggi/height (m) & 16.07 & 35.00 & 5.77 & 24.5965 \\
\hline
\end{tabular}

Pada Tabel 2 diatas menunjukkan lebar rentang ukuran dari diameter dan tinggi. Nilai rataan pengukuran yang memiliki nilai yang cukup jauh dari nilai maksimum dan minimum memberikan indikasi variasi nilai yang besar. Besaran nilai statistik pada tabel tersebut juga menunjukkan adanya pohon yang tertekan. 
Selanjutnya pada Gambar 2 berikut diperlihatkan model hubungan diameter dan tinggi dari tanaman meranti merah (Shorea parvifolia Dyer).

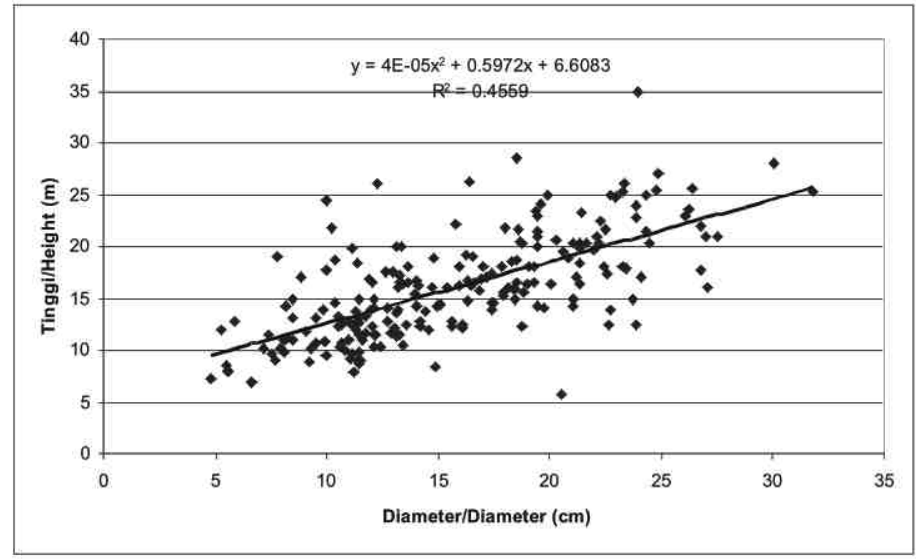

Gambar (Figure) 2. Model regresi hubungan diameter dan tinggi pada pertumbuhan tanaman meranti merah (Shorea parvifolia Dyer) di lokasi penelitian. (Regression model of relationship between diameter and heght at growth meranti merah (Shorea parvifolia Dyer) plantation in research field)

Dari Gambar 2 terlihat bahwa pertumbuhan diameter memilki hubungan yang cukup erat dengan pertumbuhan tinggi dimana hal ini ditunjukkan dengan nilai koefisien determiinasi (R2) sebesar 0,4559 atau koefisien korelasi (r) sebesar 0,6752. Selanjutnya keeratan hubungan antara diameter dan tinggi ini dapat diuji dengan nilai r-tabel pada taraf signifikansi 0,01 yang memiliki nilai 0,208 dengan derajat bebas $(n-2)=211$. Dari hasil perhitungan diatas maka nilai $r$-hitung $(0,675)>r$-tabel $(0,208)$ sehingga diantara kedua peubah tersebut terdapat hubungan yang signifikan.

Lebih jauh lagi untuk melihat tingkat signifikansi keeratan dari pertumbuhan diameter dan tinggi dilakukan analisis varian. Hasil analisis ditunjukkan dalam Tabel 3 berikut.

Tabel (Table) 3. Analisis Varian (ANOVA) hubungan pertumbuhan diameter dan tinggi untuk tanaman meranti merah (Shorea parvifolia Dyer) di lokasi penelitian. (Analysis of variance relationship growth of diameter and height meranti merah (Shorea parvifolia Dyer) plantation in research field)

\begin{tabular}{|l|r|r|r|r|r|}
\hline \multicolumn{1}{|c|}{$\begin{array}{c}\text { Variabel/ } \\
\text { Variable }\end{array}$} & $\begin{array}{c}\text { Derajat bebas/ } \\
\text { degree of freedom }\end{array}$ & $\begin{array}{c}\text { Sum of Squarel } \\
\text { jumlah kuadrat }\end{array}$ & $\begin{array}{c}\text { Mean of squarel } \\
\text { rataan kuadrat }\end{array}$ & Fhit & $\mathrm{F}_{\text {tab99\%/ }}$ \\
\hline $\begin{array}{l}\text { Regresi/ } \\
\text { Regression }\end{array}$ & 2 & 2377.241 & 1188.621 & 87.97658 & 4.61 \\
\hline Sisa/Residual & 210 & 2837.236 & 13.51065 & & \\
\hline Jumlah/Total & 212 & 5214.477 & & & \\
\hline
\end{tabular}

Hasil analisis varian menunjukkan bahwa besarnya nilai $\mathrm{F}$ hitung $>\mathrm{F}$ tabel $99 \%$ yang memberikan arti bahwa keduanya memiliki hubungan yang sangat signifikan dimana dengan bertambahnya diameter akan berpengaruh terhadap pertumbuhan tinggi. 


\section{Riap Tanaman}

Hasil perhitungan riap tanaman pertahun (Mean Annual Increment/MAI) untuk diameter dan tinggi dapat dilihat pada Tabel 4 berikut.

Tabel (Table) 4. Riap diameter dan tinggi tanaman meranti merah (Shorea parvifolia Dyer) di lokasi penelitian. (Increment of diameter and height meranti merah (Shorea parvifolia Dyer) plantation in research field)

\begin{tabular}{|l|r|r|r|r|r|}
\hline \multicolumn{1}{|c|}{ Riap/Increment } & $\begin{array}{c}\text { Rataan } \\
(\text { Mean })\end{array}$ & \multicolumn{1}{|c|}{$\begin{array}{c}\text { Maksimum } \\
(\text { Maximum })\end{array}$} & $\begin{array}{c}\text { Minimum } \\
\text { (Minimum) }\end{array}$ & $\begin{array}{c}\text { Kesalahan baku } \\
\text { (Standard } \\
\text { deviation })\end{array}$ & \multicolumn{1}{c|}{$\begin{array}{c}\text { Variasi } \\
\text { (variance) }\end{array}$} \\
\hline $\begin{array}{l}\text { Diameter/ } \\
\text { diameter }(\mathrm{cm})\end{array}$ & 1.21648 & 2.4485 & 0.3721 & 0.4302 & 0.1851 \\
\hline Tinggi/height $(\mathrm{m})$ & 1.2357 & 2.6923 & 0.4437 & 0.3815 & 0.1455 \\
\hline
\end{tabular}

Dari Tabel 4 diatas terlihat bahwa rataan riap diameter tanaman pertahun mencapai $1,22 \mathrm{~cm}$ pertahun, nilai ini sebenarnya didapat dari perbedaan nilai riap dengan rentang yang cukup yang dimulai dari nilai 0,37 sampai $2,44 \mathrm{~cm}$ pertahun sehingga nilai rataan ini tidak dapat menggambarkan nilai yang baik untuk dapat dikatakan mewakili dari nilai secara keseluruhan. Demikian juga yang terjadi pada pertumbuhan tinggi.

\section{Kerampingan Pohon}

Kerampingan pohon ditunjukkan berdasarkan perbandingan tinggi dan diameter (H/D). Nilai yang didapat akan menunjukkan bagaimana pohon tersebut membentuk dirinya agar tetap tahan berdiri tegak.

Suyana (2003) menyatakan bahwa nisbah atau perbandingan tinggi dan diameter adalah angka yang menunjukkan tinggi total dibagi dengan diameter yang masing-masing mempunyai satuan yang sama, sehingga angka yang diperoleh merupakan angka indeks tanpa satuan. Angka ini penting diketahui untuk menilai bentuk arsitektur batang pohon.

Dari hasil perhitungan diperoleh nilai rataan H/D sebesar 107,96. Nilai tersebut menunjukkan bahwa pohon ini memiliki arsitektur cukup ramping karenanya diperlukan perlakuan khusus pada tegakan ini guna memacu pertumbuhan diameter untuk menghindari pohon terlalu tinggi tanpa ditopang oleh diameter yang besar. Sebagaimana diketahui jika pohon memiliki tinggi yang tidak ditopang oleh diameter yang besar akan memberikan indikasi pohon ini riskan terhadap angin. Nilai kerampingan ini adalah berbanding lurus untuk dapat memberikan informasi kekuatan tanaman. Selanjutnya Sutisna (2000) dalam Suyana (2003) berpendapat bahwa bagi pohon-pohon di hutan alam yang berperawakan bagus mempunyai angka H/D $\leq 100$. Lebih dari 100 berarti pohon "letoy" atau mudah roboh diterpa angin dan apabila kurang dari 100 berarti pohon kekar. 


\section{KESIMPULAN DAN SARAN}

\section{A. Kesimpulan}

Dari hasil pembahasan diatas maka dapat ditarik beberapa kesimpulan sebagai berikut:

1. Struktur tegakan atau pola sebaran diameter memiliki bentuk Genta atau kurva Normal sebagaimana sebaran pada hutan tanaman.

2. Terdapat rentang perbedaan yang besar dari besar nilai diameter dan tinggi, demikian juga dengan besarnya riap diameter dan tinggi tersebut. Walaupun demikian nilai rataan riap pertahun sebesar $1,22 \mathrm{~cm}$ pertahun untuk diameter dan 1,24 m pertahun untuk tinggi.

3. Pohon dapat dikatakan cukup ramping dengan rataan nisbah tinggi dengan diameter sebesar $107,96$.

\section{B. Saran}

Hasil pengamatan ini merupakan informasi dari pertumbuhan meranti merah (Shorea parvifolia Dyer) sampai pada umur 13 tahun sehingga masih perlu ditindaklanjuti dengan tetap mengamatinya secara periodik. Selain itu perlu diupayakan perlakuan silvikultur untuk dapat memacu pertumbuhan diameter.

\section{DAFTAR PUSTAKA}

Anonim 1992. Manual Kehutanan. Departemen Kehutanan. Jakarta.

Anonim 1994. Timber Trees: Major Commercial Timber. Plant Resources of South - East Asia PROSEA) No. 5 (1). Bogor.

Daniel T.W, J.A. Helmes and F.S Baker, 1979. Prinsip-prinsip Silvikultur (Terjemahan Djoko Marsono) Gadjah Mada University Press. Yogyakarta.

Davis, K.P, 1966. Forest Management. McGraw-Hill Book, Co. New York.

Evans, J. 1982. Plantatioan Forestry In the Tropics. Clarendon Press- Oxford, New York.

Heyne, K. 1987. Tumbuhan Berguna Indonesia III (Terjemahan). Badan Penelitian dan Pengembangan Kehutanan, Departemen Kehutanan. Jakarta

Loetch, F. Zohrer, F. and Haller, K.E., 1973. Forest Inventory Vol II. Forest Inventory Section. Federal Research Organization Far Forest and Forest Products, Reinbeck. BLV. Verlagsgeselll Schaft Munchen Bern Wien.

Martawijaya. A,. I. Kartasujana, K. Kadir dan S.A. Prawiwira. Atlas Kayu Indonesia. Jilid I. Badan Penelitian dan Pengembangan Kehutanan, Departemen Kehutanan. Bogor

Schmidt, F. H. \& J. H. A. Ferguson. 1951. Rainfall Type Based on Wet and Dry Period Ratios for Indonesia with Western New Guinea. Verhand 42. Direktorat Meteorologi dan Geofisika. Jakarta. 
Snedecor, G. and W.G. Cochran. 1967. Statistical Methods Sixth Ed. The Iowa State University Press. Ames Iowa. USA

Steel, R.G.D. dan J.H. Torrie. 1993. Prinsip dan Prosedur Statistika, Suatu Pendekatan Biometrika. PT. Gramedia Pustaka utama. Jakarta.

Sutisna. M. 1998. Silvikultur Hutan Alam di Indonesia. Fakultas Kehutanan Universitas Mulawarman. Samarinda.

Suyana. A, 2003. Dampak Penjarangan Terhadap Struktur Tegakan dan Pertumbuhan Tegakan di Hutan Produksi Alami PT Inhutani I Labanan, Kabupaten Berau. Tesis Pasca Sarjana, Universitas Mulawarman. Samarinda. (tidak diterbitkan)

Suyana, A dan Abdurachman, 2006. Kondisi Tegakan Shorea leprosula Miq. Umur 13 tahun pada berbagai Jarak Tanam di KHDTK Sebulu, Kabupaten Kutai Kartanegara, Kalimantan Timur. Prosiding Seminar Bersama Hasil-hasil Penelitian. Balai Litbang Kehutanan Kalimantan, Balitbang Hutan Tanaman, Loka Litbang Satwa Primata. Samarinda.

Rizal. A. 1987. Studi Tentang Pengaruh Penjarangan Terhadap Pertumbuhan Tegakan Acacia mangium Wild. Pada Periode 1983-1987. Skripsi Fakultas Kehutanan Unmul (tidak diterbitkan). Samarinda.

Usman, H. dan R.P.S. Akbar, 1995. Pengantar Statistika. Penerbit Budi Aksara. Jakarta. 